\title{
Patient Satisfaction with and Acceptance of Their Totally-Implanted Central Venous Catheter: Construction and First Validation of a Questionnaire
}

\author{
Pierre Yves Marcy ${ }^{1}$, Véronique Mari ${ }^{2}$, Andréa Figl ${ }^{3}$, Isabelle Ben-Taarit ${ }^{1}$, Yves Fouché ${ }^{3}$ \\ Frédéric Peyrade², Philippe Follana², Cécile Michel4, Emmanuel Chamorey ${ }^{4}$ \\ ${ }^{1}$ Department of Radiology, Centre Antoine Lacassagne, Nice, France \\ ${ }^{2}$ Department of Medical Oncology, Centre Antoine Lacassagne, Nice, France \\ ${ }^{3}$ Department of Surgery, Centre Antoine Lacassagne, Nice, France \\ ${ }^{4}$ Department of Clinical Research, Innovation and Statistics, Centre Antoine Lacassagne, Nice, France \\ Email: *pymarcy@icloud.com
}

Received 15 April 2014; revised 12 May 2014; accepted 10 June 2014

Copyright (C) 2014 by authors and Scientific Research Publishing Inc.

This work is licensed under the Creative Commons Attribution International License (CC BY). http://creativecommons.org/licenses/by/4.0/

(c) (i) Open Access

\begin{abstract}
Rationale: Most cancer patients require a totally-implanted Central Venous Catheter (CVC) for their treatment. We develop and validate a French-language questionnaire dubbed QASICC (Questionnaire for Acceptance of and Satisfaction with Implanted Central Venous Catheter) assessing patient satisfaction with and acceptance of their CVC. Method: The construction and first validation of the questionnaire was made using validated methodology consisting in four phases. Phase 1 aimed at collecting a comprehensive list of relevant items. Phase 2 consisted in converting items into questions followed by a first item selection procedure. Phase 3 tested the acceptance of the provisional module to a small number of patients. Phase 4 involved a first validation on patients to determine its psychometric characteristics. Results: Responses to the questionnaire were collected from 215 patients. The final tool included 27 questions assessing seven dimensions: pain, contribution to the comfort of the treatment, esthetics and privacy, impact on professional activities, social and sports, impact on daily activities, local discomfort and overall satisfaction. Conclusions: This first statistical validation seems very promising and allows us to confirm the structure and the psychometric properties of the tool. Further validation studies are required on standard and specific populations in order to confirm these first results.
\end{abstract}

${ }^{*}$ Corresponding author.

How to cite this paper: Marcy, P.Y., et al. (2014) Patient Satisfaction with and Acceptance of Their Totally-Implanted Central Venous Catheter: Construction and First Validation of a Questionnaire. Journal of Cancer Therapy, 5, 706-716.

http://dx.doi.org/10.4236/jct.2014.57079 


\section{Keywords}

\section{Central Venous Catheter, Patient Satisfaction, Questionnaire, Cancer, Quality of Life}

\section{Introduction}

Patient satisfaction with or acceptance of care assessment is increasingly taken into account in oncology. Most cancer and other critically-ill patients require a totally-implanted Central Venous Catheter (CVC) for their treatment consisting of a reservoir connected to a central venous catheter, which may or may not be valved. It is impossible to estimate the number of CVC used in oncology. However, some authors claim that, in 2005, over 7 million CVCs were placed in the United States [1] in both chronic and acute care. Although many patients fitted with a CVC are able to undertake activities which are hindered with other external vascular access devices, they are often physically or psychologically anxious about their device [2]. To our knowledge, no validated questionnaire measuring patient acceptance of and satisfaction with their CVC has been reported in the literature. Based on these observations, the aim of our study was to develop and to validate a French-language questionnaire dubbed QASICC (Questionnaire for Acceptance of and Satisfaction with Implanted Central Venous Catheter) assessing patient satisfaction with and acceptance of their CVC. QASICC is designed as a multi-dimensional, self-administered questionnaire comprising approximately 30 items related to the use, appearance and pros and cons of the device as well as quality of life as perceived by patients using one for treatment.

\section{Materials and Methods}

The questionnaire construction and first validation process followed both the guidelines of the European Organization Research [3] and the recommendations of B. Falissard [4]. The procedure consisted in four phases. Phase 1 aimed at collecting a comprehensive list of relevant items in the field of CVC acceptance, satisfaction and quality of life. Phase 2 consisted in converting items into understandable questions followed by a first item selection procedure using the Delphi method [5]. Phase 3 administered the provisional module to a small number of patients belonging to the target population. The aim was to identify and solve potential problems and evaluate the overall level of appeal, attention and interest. We also submitted the questionnaire to the French National League Against Cancer for review. Phase 4 involved the first validation of the questionnaire by fieldtesting it on a large group of patients in order to determine its psychometric characteristics. Phase 1,2 and 3 can be considered as a qualitative step designed for item generation and construction, phase 4 as a quantitative step designed for questionnaire validation. A Steering Committee (SC) including 3 physicians (one surgeon, one radiologist and one medical oncologist), a nurse and a psychometrician/methodologist was created in order to coordinate the study.

\subsection{Qualitative Step}

\subsubsection{Phase 1}

Firstly, the SC reviewed the literature to identify relevant existing instruments or items assessing the impact of CVC on patients' daily life, as well as acceptance, quality of life and other relevant items. We set up a Focus Group (FG) of 15 persons including a broad range of health care and non-health care workers (2 nurses, 2 nurses' aides, 1 medical oncologist, 1 radiologist, 1 surgeon, 1 methodologist, 1 communication manager, 1 quality manager, 1 psychologist) and 4 patients. The FG met 3 times and was interviewed in order to complete the list with additional questions of potential interest. This process yielded 47 relevant items altogether. Secondly, twenty consecutive patients were interviewed by members of the SC to analyze their perception and acceptance of their CVC. Patients were enrolled during their hospitalization for treatment, or in the event of adverse events related to their CVC. As we were more interested in the subjects' perception of their CVC and its impact on their everyday life, these interviews were conducted one month after CVC placement. This period was sufficient for most patients to have experienced the CVC's pros and cons and short enough to allow them to remember their life before CVC placement. Subjects were asked to detail specific events they had experienced or situations associated with healthcare and pleasant and unpleasant feelings related to their CVC. The interviews were conducted in chronological order of CVC placement, use and management. Patients expressing ideas not directly related to 
the CVC were invited to refocus on the questions. Each patient was then examined by the physician and could express other feelings related to their CVC. All the different formulations of a given idea were recorded and a second list of items was generated from their statements during a SC meeting. All these new items were worded by seeking maximum respect for the idea expressed by the patient. This yielded 55 additional items.

\subsubsection{Phase 2}

The final list of 102 items was then converted into questions. The SC transformed the items into precise, intuitive, understandable and unbiased sentences in French. Each item was scored on a Likert-type scale, a yes/no checkbox or an Analogic Visual Scale from 0 to 10. The questionnaire comprising 102 items was sent to a group of 30 experts representing a broad cultural mix of professional backgrounds and regions of France. The experts included physicians, radiologists, surgeons, nurses, epidemiologists and patients who were selected for their knowledge of and interest in the CVC or in cancer treatment, for their reputation, number of publications, and their experience in the field. This group was invited to provide feedback on the first survey content using the Delphi method [5]. The aim was to reach a consensus on the list of 102 items. All items were sent by email to the experts, who were asked to score the relevance of each item on a scale from 0 to 10 . The level of understanding was also assessed on a scale ranging from 0 to 10 and the median for each item was then calculated. If the median relevance score was $<3(0-3)$, the item was rejected; if median relevance was comprised between 3 and 7 ( 3 - 7), the item was resubmitted to the experts; if median relevance was $>7$ ( 7 - 10), the item was included in the final questionnaire. The choice of these intervals was proposed according to the consensus opinion of the SC. All incomprehensible or confusing items were reformulated and resubmitted. If no consensus was found, they were removed. Thereafter, the process was iterative and three rounds were needed to obtain a consensus on 62 items.

\subsubsection{Phase 3}

This 62-item questionnaire was sent to the National League Against Cancer for review. This French nonprofit association is recognized as being of public interest as the first private and independent funder of cancer research in France. They checked acceptability, interest, wording and exhaustiveness of the item list. Then, the provisional module was tested on 20 patients representative of the target population. This was followed by structured interviews with each patient after completion of the questionnaire. This pilot study was conducted to check the comprehensibility, acceptability and response patterns. The list of 62 items extracted from this qualitative phase and the response modalities are shown in Table 1 . The questionnaire also comprised data on patient characteristics, socio-demographic profile and medical status.

Table 1. Results of the quantitative step of QASICC validation (items, results from factorial analysis, dimensions).

\begin{tabular}{|c|c|c|c|c|c|c|c|c|c|}
\hline छ & 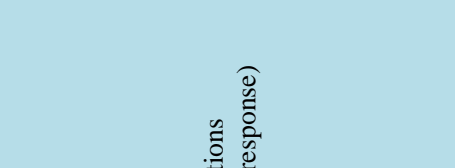 & 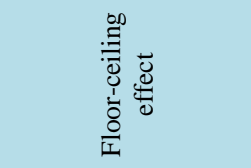 & 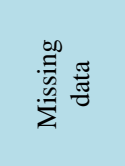 & & & 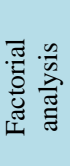 & & 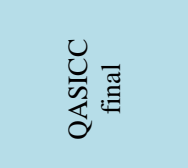 & 意 \\
\hline$\dot{z}$ & 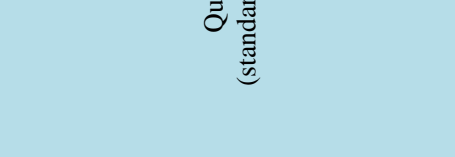 & $\frac{\mathfrak{o}}{\dot{0}}$ & $\frac{\partial}{\stackrel{0}{0}}$ & 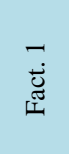 & 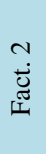 & 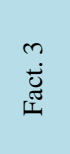 & 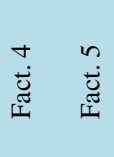 & $\begin{array}{l}\text { चี } \\
\dot{\Xi} \\
\dot{0}\end{array}$ & 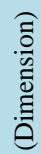 \\
\hline 1 & Is your device too visible? (b) & $56(37.0)$ - $97(63.0)$ & $62(28.8)$ & 0.37 & & & & Q11 & 1 \\
\hline 2 & $\begin{array}{l}\text { Did it hurt when the device is } \\
\text { inserted? (f) }\end{array}$ & {$[0-0.2-1 \cdot 0-3 \cdot 2-10]^{*}$} & $71(33.0)$ & & & & & Q1 & 6 \\
\hline 3 & $\begin{array}{l}\text { Does your device hurt when the needle } \\
\text { is inserted? (e) }\end{array}$ & $3(1.9)-88(56.0)$ & $58(27.0)$ & & & & & Q2 (G: 3, 4, 5) & 6 \\
\hline 4 & $\begin{array}{l}\text { Does your device hurt during the drug } \\
\text { infusion? (e) }\end{array}$ & $0(0.0)-131(89.7)$ & $69(32.1)$ & & & & & Q2 (G: 3, 4, 5) & 6 \\
\hline 5 & $\begin{array}{l}\text { Does your device hurt when the needle } \\
\text { is removed? (e) }\end{array}$ & $2(1.4)-112(76.7)$ & $69(32.1)$ & & & & & Q2 (G: 3, 4, 5) & 6 \\
\hline
\end{tabular}




\section{Continued}

\begin{tabular}{|c|c|c|c|c|c|c|c|c|}
\hline 6 & $\begin{array}{l}\text { Does your device produce a feeling of: } \\
\text { pulsing? (e) }\end{array}$ & $2(1.4)-105(74.4)$ & $74(34.4)$ & & 0.90 & & Q23 & 2 \\
\hline 7 & Penetration? (e) & $1(0.7)-117(85.4)$ & $78(36.3)$ & & & & (R) & \\
\hline 8 & Stabbing? (e) & $3(2.1)-124(89.8)$ & 77 (35.8) & & & & $(\mathrm{F} / \mathrm{C})$ & \\
\hline 9 & Crushing? (e) & $1(0.7)-130(94.8)$ & 78 (36.3) & & & & $(\mathrm{F} / \mathrm{C})$ & \\
\hline 10 & Tugging? (e) & $2(1.4)-97(71.3)$ & 79 (36.7) & & 0.73 & & Q24 & 2 \\
\hline 11 & Burning? (e) & $2(1.4)-122(86.5)$ & $74(34.4)$ & & 0.78 & & Q25 & 2 \\
\hline 12 & Pins and needles? (e) & $1(0.7)-117(84.1)$ & 76 (35.3) & & 0.72 & & Q26 & 2 \\
\hline 13 & Heaviness? (e) & $2(1.4)-123(89.1)$ & 77 (35.8) & & & & $(\mathrm{F} / \mathrm{C})$ & \\
\hline 14 & Exhaustion? (e) & $1(0.7)-133(96.3)$ & 77 (35.8) & & & & $(\mathrm{F} / \mathrm{C})$ & \\
\hline 15 & Agony? (e) & $1(0.7)-118(86.1)$ & 78 (36.3) & & & 0.52 & Q21 & 4 \\
\hline 16 & Obsessiveness? (e) & $1(0.7)-123(89.1)$ & 77 (35.8) & & & & $(\mathrm{F} / \mathrm{C})$ & \\
\hline 17 & Intolerableness? (e) & $0(0.0)-129(94.8)$ & 79 (36.7) & & & & $(\mathrm{F} / \mathrm{C})$ & \\
\hline 18 & Annoyance? (e) & $2(1.4)-114(82.0)$ & $76(35.3)$ & & & 0.76 & Q22 & 4 \\
\hline 19 & Troublesomeness? (e) & $1(0.7)-130(95.5)$ & 79 (36.7) & & & & $(\mathrm{F} / \mathrm{C})$ & \\
\hline 20 & Wretchedness? (e) & $3(2.1)-124(89.8)$ & 77 (35.8) & & & & (R) & \\
\hline 21 & $\begin{array}{l}\text { Do you perceive your device as a } \\
\text { foreign body? (c) }\end{array}$ & $57(36.3)-100(63.7)$ & $58(27.0)$ & 0.60 & & & Q6 & 1 \\
\hline 22 & $\begin{array}{l}\text { Physically. How easy is it for you to } \\
\text { show your device for care? (d) }\end{array}$ & $0(0.0)-87(55.0)$ & 57 (26.5) & 0.39 & & & Q5 (G: 22, 23) & 1 \\
\hline 23 & $\begin{array}{l}\text { Psychologically. How easy is it for } \\
\text { you to show your device for care? (d) }\end{array}$ & $1(0.65)-84(54.2)$ & 60 (27.9) & 0.39 & & & Q5 (G: 22, 23) & 1 \\
\hline 24 & $\begin{array}{l}\text { How easily do you feel the nurses } \\
\text { manage to insert or remove the } \\
\text { needle? (d) }\end{array}$ & $9(5.8)-147(94.2)$ & $59(27.4)$ & & & 0.44 & Q3 (G: 24, 44) & 5 \\
\hline 25 & $\begin{array}{l}\text { Does your device causes you any } \\
\text { trouble when you're: } \\
\text { Doing strenuous activities like } \\
\text { carrying a heavy shopping bag or a } \\
\text { suitcase? (e) }\end{array}$ & $12(8.2)-76(52.1)$ & $69(32.1)$ & & 0.84 & & $\begin{array}{c}\text { Q14 } \\
\text { (G: 25, 26, 27) }\end{array}$ & 3 \\
\hline 26 & $\begin{array}{l}\text { Wearing a bag with a shoulder strap? } \\
\text { (e) }\end{array}$ & $7(5.1)-83(60.1)$ & 77 (35.8) & & 0.84 & & Q14 (G: 25, 26, 27) & 3 \\
\hline 27 & Wearing car seat belt? (e) & $12(7.8)-105(68.6)$ & $62(28.8)$ & & 0.84 & & Q14 (G: 25, 26, 27) & 3 \\
\hline 28 & Doing physical activities or sports? (e) & $7(5.2)-88(65.7)$ & $81(37.7)$ & & 0.83 & & Q20 & 3 \\
\hline 29 & $\begin{array}{l}\text { Sitting at rest watching TV or reading? } \\
\text { (e) }\end{array}$ & $2(1.3)-126(81.8)$ & $61(28.4)$ & & & 0.89 & Q16 (G: 29, 30) & 4 \\
\hline 30 & Sleeping? (e) & $3(2.0)-107(70.4)$ & $63(29.3)$ & & & 0.89 & Q16 (G: 29, 30) & 4 \\
\hline 31 & $\begin{array}{l}\text { Does your device causes you any } \\
\text { trouble when you're: } \\
\text { Engaged in social activities (shopping, } \\
\text { going to movies, going out with } \\
\text { friends...)? (e) }\end{array}$ & $0(0.0)-125(87.4)$ & $72(33.5)$ & & 0.57 & & Q18 (G: 31, 32) & 3 \\
\hline 32 & Engaged in professional activities? (e) & $5(4.5)-101(90.2)$ & $103(47.9)$ & & 0.57 & & Q18 (G: 31, 32) & 3 \\
\hline 33 & $\begin{array}{l}\text { Concentrating on activities such as } \\
\text { writing, reading a newspaper, ...? (e) }\end{array}$ & $0(0.0)-138(93.9)$ & $68(31.6)$ & & & & $(\mathrm{F} / \mathrm{C})$ & \\
\hline 34 & Speaking or eating in public? (e) & $1(0.7)-135(93.8)$ & $71(33.0)$ & & & & $(\mathrm{F} / \mathrm{C})$ & \\
\hline 35 & $\begin{array}{l}\text { When someone watching you or when } \\
\text { someone talking to you? (e) }\end{array}$ & $1(0.7)-136(89.5)$ & $63(29.3)$ & & & & $(\mathrm{F} / \mathrm{C})$ & \\
\hline 36 & Engaged in family life? (e) & $1(0.7)-142(93.4)$ & $63(29.3)$ & & & & $(\mathrm{F} / \mathrm{C})$ & \\
\hline
\end{tabular}




\section{Continued}

\begin{tabular}{|c|c|c|c|c|c|c|c|c|}
\hline 37 & $\begin{array}{l}\text { Engaged in intimacy with your } \\
\text { spouse? (e) }\end{array}$ & $6(4.2)-109(76.2)$ & $72(33.5)$ & 0.72 & & & Q19 & 1 \\
\hline 38 & For aesthetic reasons? (e) & $9(0.1)-98(65.3)$ & $65(30.2)$ & 0.80 & & & Q17 (G: 38, 41) & 1 \\
\hline 39 & Wearing a bra? (e) & $4(3.1)-100(78.1)$ & $87(40.5)$ & & & & $(\mathrm{R}, \mathrm{M})$ & \\
\hline 40 & Dressing and undressing? (e) & $2(1.4)-113(76.4)$ & $67(31.2)$ & & 0.47 & & Q15 & 4 \\
\hline 41 & Looking at yourself in a mirror? (e) & $3(2.0)-112(75.7)$ & $67(31.2)$ & 0.89 & & & Q17 (G: 38, 41) & 1 \\
\hline \multirow[t]{2}{*}{42} & Do you feel inferior to others? (e) & $2(1.3)-129(0.9)$ & $65(30.2)$ & & & & $(\mathrm{F} / \mathrm{C})$ & \\
\hline & Advantages of your CVC & & & & & & & \\
\hline 43 & Does it spare your veins? (a) & $77(49.7)-78(50.3)$ & $60(27.9)$ & & & & $(\mathrm{O})$ & \\
\hline 44 & $\begin{array}{l}\text { Does it facilitate the process for drug } \\
\text { infusion? (b) }\end{array}$ & $88(56.8)-67(43.2)$ & $60(27.9)$ & & & 0.44 & Q3 (G: 24, 44) & 5 \\
\hline 45 & $\begin{array}{l}\text { Bothers you when you do your local } \\
\text { hygiene? (b) }\end{array}$ & $106(68.4)-49(31.6)$ & $60(27.9)$ & & & 0.65 & Q12 (G: 45, 47) & 5 \\
\hline 46 & Is it discrete? (b) & $122(78.7)-33(21.3)$ & $60(27.9)$ & & & & $(\mathrm{R})$ & \\
\hline 47 & $\begin{array}{l}\text { Does it make washing yourself easier? } \\
\text { (b) }\end{array}$ & 127 (81.9) - $28(18.1)$ & $60(27.9)$ & & & 0.65 & Q12 (G: 45, 47) & 5 \\
\hline 48 & Is it quick to use? (b) & $128(82.6)$ - $27(17.4)$ & $60(27.9)$ & & & & (R) & \\
\hline 49 & Is it comfortable during injections? (b) & 96 (61.9) - 59 (38.1) & $60(27.9)$ & & & 0.42 & Q4 & 5 \\
\hline 50 & $\begin{array}{l}\text { Does it give you freedom of } \\
\text { movement? (b) }\end{array}$ & $125(80.7)-30(19.4)$ & $60(27.9)$ & & & & $(\mathrm{R})$ & \\
\hline $5 a$ & Can you use it at home? (a) & $142(91.6)-13(8.4)$ & $60(27.9)$ & & & & $(\mathrm{F} / \mathrm{C}, \mathrm{R})$ & \\
\hline \multirow[t]{2}{*}{52} & Is it stressful? (b) & $139(89.7)-16(10.3)$ & $60(27.9)$ & & & & $(\mathrm{F} / \mathrm{C}, \mathrm{R})$ & \\
\hline & Disadvantages of your CVC & & & & & & & \\
\hline 53 & Reminder of the disease? (c) & $118(76.6)-36(23.4)$ & $61(28.4)$ & 0.49 & & & Q8 & 1 \\
\hline 54 & It is difficult to find it? & $151(98.1)-3(2.0)$ & $61(28.4)$ & & & & $(\mathrm{F} / \mathrm{C})$ & \\
\hline 55 & Globus sensation? (b) & $137(89.0)-17(11.0)$ & $61(28.4)$ & & 0.27 & & Q13 & 3 \\
\hline 56 & Fear of hurting or damaging CVC? (c) & $131(85.1)-23(14.9)$ & $61(28.4)$ & & & 0.34 & 7 & 5 \\
\hline 57 & Fear of your CVC being blocked? (c) & $142(92.2)-12(7.8)$ & $61(28.4)$ & & & & Q10 & 5 \\
\hline 58 & $\begin{array}{l}\text { Vulnerability and fragility of the } \\
\text { CVC? (c) }\end{array}$ & $153(99.4)-1(0.7)$ & $61(28.4)$ & & & & $(\mathrm{F} / \mathrm{C})$ & \\
\hline 59 & Discomfort on touching the CVC? (b) & $141(91.6)-13(8.4)$ & $61(28.4)$ & & & & Q9 & 3 \\
\hline 60 & Discomfort in the shower? (b) & 149 (96.8) - 5 (3.3) & $61(28.4)$ & & & & $(\mathrm{F} / \mathrm{C}, \mathrm{R})$ & \\
\hline 61 & Always thinking of your CVC? (c) & $151(98.1)-3(2.0)$ & $61(28.4)$ & & & & $(\mathrm{F} / \mathrm{C}, \mathrm{R})$ & \\
\hline 62 & $\begin{array}{l}\text { Overall satisfaction with your CVC? } \\
\text { (f) }\end{array}$ & {$[1.6-6 \cdot 2-7.3-7.8-10]^{*}$} & & & & & Q27 & 7 \\
\hline
\end{tabular}

Item: Number of the 62 items collected in phases 2 and 3 of the qualitative step. Items retained for the final QASICC questionnaire are shown in bold. Question (response type): Questions have been translated into English only for the purpose of the article. The response types are described in brackets. Response types: (a) Binary (yes/no). (b) Likert: 0 (Not at all), 1 (Somewhat), 2 (A lot), 3 (Extremely). (c) Likert: 0 (Never), 1 (Sometimes), 2 (Often), 3 (Always). (d) Likert: 0 (Very easy), 1 (Rather easy), 2 (Rather difficult), 3 (Very difficult). (e) Likert: 0 (No), 1 (Low), 2 (Moderate), 3 (High). (f) Analogic Visual Scale (0 - 10). Floor-Ceiling effect: The floor and ceiling effects are described by using range and quartile for quantitative data (Analogic visual scale) or by showing the extreme response absolute and relative frequency for Likert scales. Missing data: Absolute and relative frequency for missing data. Factorial analysis: Factorial analysis with varimax rotation; only the highest factor is given in the table. QASICC final: Q(n) indicates the number of the final question in the QASICC questionnaire. In brackets: (R) This item has been removed to avoid repetition. When items showed high level correlation and evaluated the same characteristic, SC could removed this item consensually. (F/C) This item has been removed on account of a floor/ceiling effect. Too much patient the same answer to the question, the item is not relevant. (G) These items have been grouped together + number of the grouped items. When items showed high level correlation but evaluated the same characteristics by different point of view. (M) This item has been removed because of too much missing data. (O) This item has been removed because formulation was complicated and some patient didn't really understand the sense of the item. Only well-informed patients could answer the item correctly. Factor (dimension): Indicates the factor (dimension) of the final tool. 1: Appearance, esthetics, privacy. 2: Local discomfort. 3: Professional, social activity and sport. 4: Daily personal activity. 5: Contribution to treatment and comfort. 6: Pain during placement and use. 7: Overall satisfaction. 


\subsection{Quantitative Step}

\section{Phase 4}

The module of 62 items was then evaluated on a large cohort of patients (215). The questionnaire was administered during a monocentric randomized controlled trial aimed to compare surgically-inserted chest ports and radiologically-inserted arm ports for CVC in terms of mechanical, thrombotic and infectious adverse events. The questionnaire was administered once, four weeks after CVC placement. Were eligible: adults with a diagnosis of solid tissue malignancy, beginning a course of intermittent bolus intravenous chemotherapy with an expected life expectancy of 3 months or longer, WHO staging criteria $<3$. The type of catheter consisted of totally implantable ports with silicone-coated catheters (Districath 225PM, Districlass médical SA Saint-Etienne France) in the surgical group, and MRI-low profile BardPort, (Bard Access Systems, Salt Lake City UT, USA), in the radiological group. Qualified nurses were responsible for maintaining all of the catheters, which were flushed with heparin solution after each infusion using positive pressure at Huber needle retrieval. Before use, the checking procedure included blood return control at syringe suction and subsequent $10 \mathrm{ml}$ saline solution flushing, and device filling with $5 \mathrm{ml}$ of a solution containing $50 \mathrm{UI} / \mathrm{ml}$ of heparin sodium (Heparine Sodique; Dakota, Créteil, France). The study was approved by a French ethical committee. Informed written consent was obtained from all participants before enrolment in the study.

\subsection{Statistical Analysis}

Item quality was evaluated using non-response, saturation effects (ceiling effect, floor effect) and redundancies. These features were evaluated using descriptive statistics: percentage of missing values, response rates, minimum, maximum, median, standard deviation, histograms, and paired correlations of items. The dimensional structure of the questionnaire was obtained using exploratory approaches such as diagrams of eigenvalues and eigenvalues, and maximum-likelihood factor analysis with varimax rotation. We also used multi-trait and multimethod analysis. This latter method is simpler and more robust and can be used to confirm the proposed structure of the instrument. The principle is that items belonging to the same subscale should be highly correlated with one another. The consistencies of the dimensions are estimated by Cronbach's alpha and 95\% confidence interval evaluated by the bootstrap method. Reliability of the questionnaire is not evaluated in this first validation procedure. Descriptive statistics and analysis were made by R.2.12.2 with a significance level of 5\% in bilateral hypothesis. All these analyses were computed with both the original data and extrapolated missing data using multiple imputations. All the results presented are from database including data extrapolated by using multiple imputations. Only Table 1 is from the original data set.

\section{Results}

\subsection{Qualitative Step (Phases 1, 2, 3)}

ST literature searches and FG interviews revealed 47 relevant items. This provisional list was then completed with 55 items from patient interviews. At this step, the first draft of our questionnaire included 102 items of varying relevance or redundancy. Each item was then carefully evaluated and worded in precise question form by the ST. These 102 items were then presented to the group of experts to obtain feedback on the first survey content using the Delphi method [5]. At this stage, 42 of the 47 items proposed by the ST/FG and 20 of the 55 items proposed by patients were retained. Finally, the questionnaire was tested on 20 patients using CVC for their treatment at our anticancer center. All questions seemed to be well-accepted and understood and no item was omitted or modified.

\subsection{Quantitative Step (Phase 4)}

A total of 215 adult patients with solid tissue malignancies were enrolled in a prospective randomized phase 3 study. Responses to the questionnaire were collected from all 215 patients 4 weeks after their inclusion in the study. The analyzed patients comprised 106 CVC (49.3\%) assigned to the surgical insertion procedure (chest port insertion) and 109 CVC (50.7\%) assigned to the radiological insertion procedure (arm port insertion) making a total of 32,075 and 29,007 CVC days, respectively. Median patient age was 59.4 years [range: 25.7 - 83.0], 120 men (55.8\%) and 95 women (44.2\%); 149 patients (71.3\%) had an advanced stage 3 or 4 disease. Location 
of tumor site was: 69 breast (32.1\%), 44 head and neck (20.5\%), urology/gynecology 32 (14.9\%), brain 28 (13.0\%), lung 16 (7.4\%), digestive 15 (7.0\%) and other cancer 11 (5.1\%).

\subsection{Item Selection}

A first selection of items was made by observing their characteristics and the distribution of each of them. All are summarized in Table 1 using descriptive statistics and figures. Criteria for selection or rejection of items were first based on rates of non-response and missing data (M). The distribution of each item was evaluated in order to detect ceiling (C) and floor effects (F). The redundancy (R) between items was evaluated using an interitem Spearman matrix correlation table. When Spearman Rho was $<0.30$, the two questions were suspected to be redundant. All descriptive statistics were presented by the methodologist to the steering committee. All selected or rejected items were carefully analyzed. The decision to reject item was made taking into account both analytical data and healthcare arguments. All items were analyzed independently, but also by placing each within its respective item family. When questions concerned the same area, the data were analyzed taking into account each object relative to others. This first item selection was conducted taking into account all of the characteristics for each item and for each group of items. If an item was considered essential by the steering committee but the descriptive analysis seemed poor, the question was still kept in the questionnaire. Following the phase of item selection, the steering committee retained 27 of the 62 initially proposed questions (Table 1).

\subsection{Factorial Structure of the Tool}

The number of dimensions of the instrument was first revealed by using scree plot analysis. Figure 1 shows that five factors can be expected. Eigenvalues of the first 5 dimensions of the scree plot analysis were: 5.40; 2.80; $1.87 ; 1.80$ and 1.63, respectively. We then analyzed analytical results from the factorial analysis with varimax rotation including 5 factors (dimensions) (Table 1). The five main factors seemed relatively well-identified except for items 2, 3, 4, 5 measuring pain and item 62 evaluating overall satisfaction. These five items were analyzed precisely, two of them were left unchanged and the other three were grouped into a single item relative to pain.

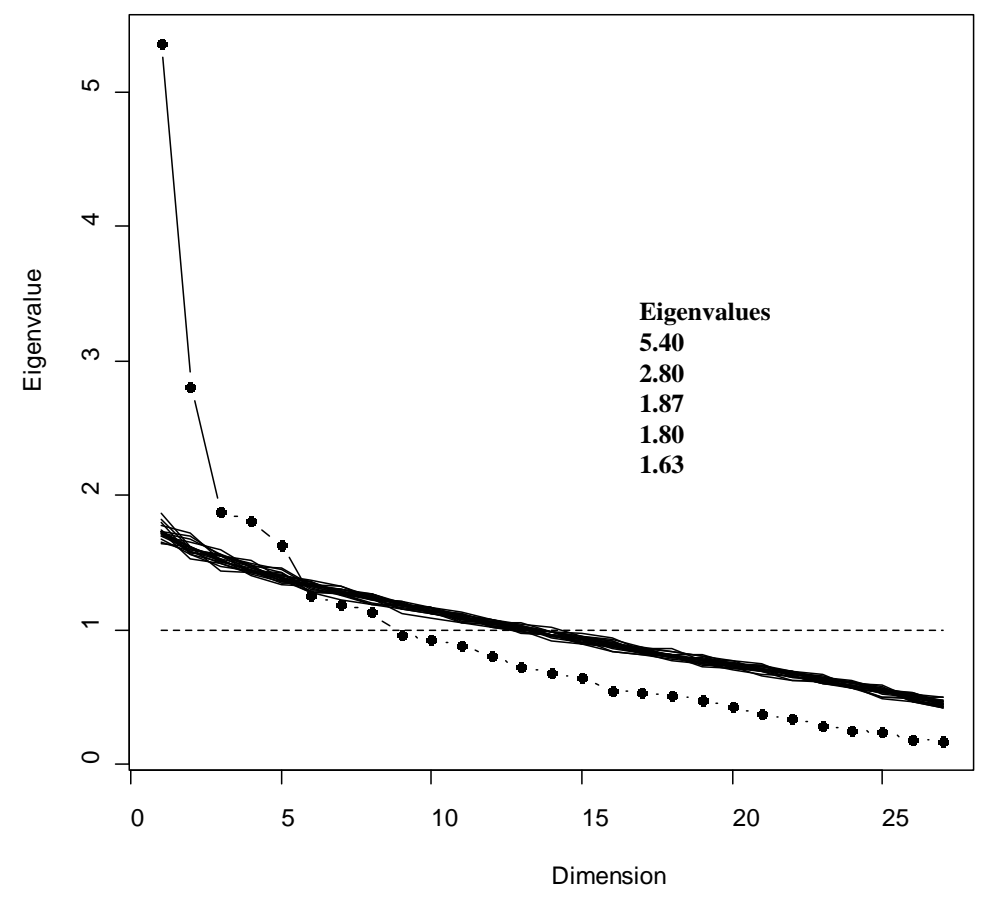

Figure 1. Scree plot of eigenvalues and 20 simulated data (multiple imputation). Graphical representation of eigenvalues of the correlation matrix. Simulations are proposed to assist interpretation. The graph shows a structure comprising 5 dimensions. 


\subsection{Internal Validity of the Tool Subscales}

The validity of our tool subscales was evaluated using a MultiTrait-Multimethod Matrix (MTMM). Figure 2 shows the graphical MTMM for the 5 factors in the questionnaire. The Cronbach coefficient and 95\% confidence interval were 0.77 [0.72 - 0.81], 0.77 [0.73 - 0.79], 0.79 [0.74 - 0.84], 0.81 [0.73 - 0.87 ] and 0.52 [0.38 0.61 , respectively for scales $1,2,3,4,5$.

\subsection{First Validated Questionnaire and Scoring Manual}

After this first validation, the final tool shown in Table 1 included 27 questions (Q) assessing seven dimensions: pain during placement or use (Q1, Q2), contribution to the comfort of the treatment (Q3, Q4, Q7, Q10, Q12), esthetics and privacy (Q5, Q6, Q8, Q11, Q17, Q19), the impact on professional activities, social and sports (Q9, Q13, Q14, Q18, Q20), the impact on daily activities (Q15, Q16, Q21, Q22), local discomfort (Q23, Q24, Q25, Q26) and overall satisfaction (Q27). The device-related answers were of two types: Likert or visual analogic scale. Four types of Likert response were available: “no”, "low," "moderate,” "significant,”/“never," "sometimes,” “often,” “always”/“very easy”, “easy”, “difficult”, “very difficult”/“not at all”, “somewhat”, “a lot”, "extremely”. These questions are scored 0, 33, 67, 100, respectively, when the scores are correlated with symptoms, or 100, 67, 33, 0 when the scores are inversely correlated with symptoms. Visual analogic scales (VAS) have a length of $100 \mathrm{~mm}$. The score represents the number of mm measured on the scale. A mean score of acceptance and satisfaction can be calculated on a scale of 0 to 100 for all seven dimensions using the following formula: $\{(100$-score DO) + CO + score (score ES-100) + (100-PR score $)+(100$-ES score $)+($ score 100 -IN) + SA score $\} / 7$. Plus the overall score, the higher the acceptance and patient satisfaction is high. Missing data entail elimination of the issue from the scale score. The number of missing items is subtracted from the denominator when calculating the score. Table 2 summarizes the scoring manual used with the instrument.
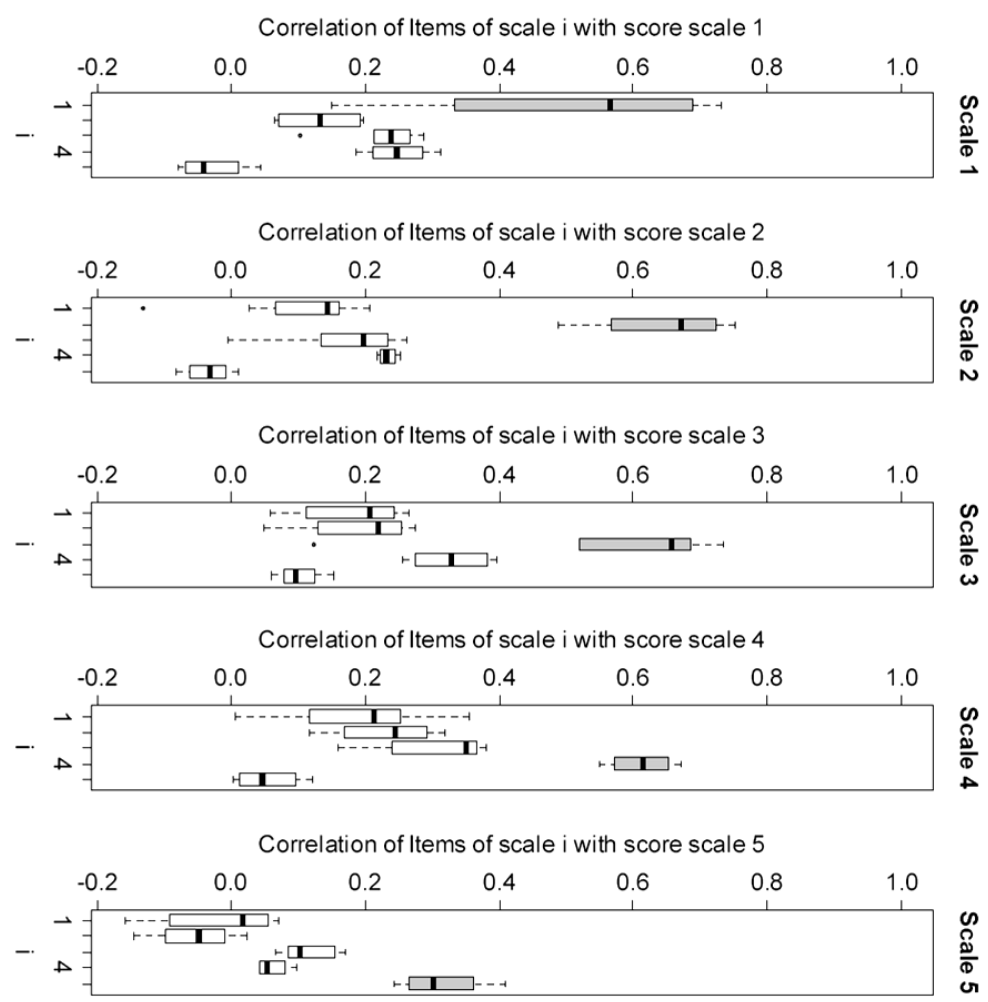

Figure 2. Internal validity of the QASICC subscales by MultiTrait Multimethod Matrix (MTMM). Missing data are extrapolated by using multiple imputation.This function is destinated to assess the convergent and discriminant validity of subscales of a given scale (factor or dimension). Items belonging to the same scale should correlate highly amongst themselves. Items belonging to different scales should not correlate highly. 
Table 2. QASICC questionnaire scoring manual.

\begin{tabular}{|c|c|c|c|c|}
\hline Dimensions (abbreviation) & $\begin{array}{c}\text { Number of } \\
\text { items in the } \\
\text { scale }\end{array}$ & Item number & Score calculation & Score interpretation \\
\hline $\begin{array}{l}\text { Pain during placement or use } \\
\text { (DO) }\end{array}$ & 2 & Q1, Q2 & $(\mathrm{Q} 1+\mathrm{Q} 2) / 2$ & $\begin{array}{l}\text { High score indicates strong } \\
\text { pain during placement or } \\
\text { use }\end{array}$ \\
\hline $\begin{array}{l}\text { Contribution to treatment } \\
\text { comfort (CO) }\end{array}$ & 5 & $\begin{array}{l}\text { Q3, Q4, Q7, Q10, } \\
\text { Q12 }\end{array}$ & $(\mathrm{Q} 3+\mathrm{Q} 4+\mathrm{Q} 7+\mathrm{Q} 10+\mathrm{Q} 12) / 5$ & $\begin{array}{l}\text { High score indicates a large } \\
\text { contribution to treatment } \\
\text { comfort }\end{array}$ \\
\hline Esthetics and privacy (ES) & 6 & $\begin{array}{l}\text { Q5, Q6, Q8, Q11, } \\
\text { Q17, Q19 }\end{array}$ & $(\mathrm{Q} 5+\mathrm{Q} 6+\mathrm{Q} 8+\mathrm{Q} 11+\mathrm{Q} 17+\mathrm{Q} 19) / 6$ & $\begin{array}{l}\text { High score indicates a large } \\
\text { change in esthetics and } \\
\text { privacy }\end{array}$ \\
\hline $\begin{array}{l}\text { Impact on professional activities, } \\
\text { social life and sports (PR) }\end{array}$ & 5 & $\begin{array}{l}\text { Q9, Q13, Q14, } \\
\text { Q18, Q20 }\end{array}$ & $(\mathrm{Q} 9+\mathrm{Q} 13+\mathrm{Q} 14+\mathrm{Q} 18+\mathrm{Q} 20) / 5$ & $\begin{array}{l}\text { High score indicates a large } \\
\text { change in professional } \\
\text { activities, social life and } \\
\text { sports }\end{array}$ \\
\hline Impact on daily activities (QU) & 4 & $\begin{array}{l}\text { Q15, Q16, } \\
\text { Q21, Q22 }\end{array}$ & $(\mathrm{Q} 15+\mathrm{Q} 16+\mathrm{Q} 21+\mathrm{Q} 22) / 4$ & $\begin{array}{l}\text { High score indicates a large } \\
\text { change in daily activities }\end{array}$ \\
\hline Local discomfort (IN) & 4 & $\begin{array}{l}\text { Q23, Q24, } \\
\text { Q25, Q26 }\end{array}$ & $(\mathrm{Q} 23+\mathrm{Q} 24+\mathrm{Q} 25+\mathrm{Q} 26) / 4$ & $\begin{array}{l}\text { High score indicates high } \\
\text { local discomfort }\end{array}$ \\
\hline Overall satisfaction (SA) & 1 & Q27 & Q27 & $\begin{array}{l}\text { High score indicates high } \\
\text { overall satisfaction }\end{array}$ \\
\hline
\end{tabular}

\section{Discussion}

Venous port device implantation techniques have been considered safe and effective procedures for chemotherapy infusion in cancer patients. Initiated by surgeons in the 80s [6], this technique replaced the installation of an external tunnelized catheter [7], by the installation of a subclavian port or by a jugular approach [8]. Assessment of patient satisfaction with and acceptance of their device has been lacking, partly because of the lack of valid or reliable instruments. The purpose of our study was to design and validate a French-language self-administered questionnaire designed to evaluate patients' satisfaction and acceptance concerning their totally-implanted central venous catheter. Following a structured method, we retained 102 questions targeting this issue: 47 from the steering committee/focus group and 55 from patients. A group of experts selected the 62 most specific questions. This first version of the instrument was tested in a randomized clinical cancer trial comprising 215 patients needing a totally-implanted central venous device. After statistical analyses and discussions with the steering committee/focus group and the patients, a questionnaire containing 27 items was validated. Response types were dichotomous (yes/no), Likert type $(0,1,2,3)$ and Analogic visual scale. We identified 7 different aspects for assessment: appearance, esthetics, privacy/professional or social activity and sport/daily personal activity/local discomfort/contribution to treatment and comfort/pain during placement and use/overall satisfaction. Few papers have been published on this subject and most were based on non-specific or non-validated questionnaires. Lilienberg et al. [9] proposed an instrument measuring level of comfort/discomfort, usefulness and physical appearance among both nurses and patients. They evaluated satisfaction regarding three different types of venous devices used in chemotherapy using a telephone questionnaire submitted to each patient. Replies to 9 Likert questions were scored and compared for each port device. The main observation of this study showed significant differences between the three tested port systems that should be taken into consideration. The main criticism was that no formal procedure for development and/or validation of this tool has been conducted and that selected items do not cover the entire issue subject. Recently, Johansson [10] used two questionnaires related to patient perception of their implanted catheter. These instruments were first developed by two nurses and a physician and were then validated by five nurses with experience in caring for patients with catheters. Four fields were evaluated using Likert scales: patient information, discomfort, feelings of anxiety and limitations on daily patient activities. These items were only designed from the perspective of the health care workers. However, it includes some interesting items concerning patient information that is not evaluated in our questionnaire. This randomized study compared central venous catheter versus totally implantable port catheter. Overall, many pa- 
tients reported minor catheter-related feelings of anxiety. Distress during placement has been related to feelings of anxiety and procedural pain. This highlights the urgent need for good routines to prevent, identify and alleviate pain and distress during central venous placement.

Maurer et al. [11] evaluated patient satisfaction with their central venous port catheter with respect to implantation under local anesthesia. One hundred patients were evaluated using an eleven-item questionnaire. No information was given concerning the construction or validation of this questionnaire. Similar to the previous study, this inquiry also analyzed the level of patient information. In another field, Caljouw et al. [12] developed a validated and reliable self-reporting multidimensional questionnaire assessing patient satisfaction with perioperative care. They also explored the quality and amount of information given. Consequently, we believe that it could be beneficial to incorporate additional items for the assessment of the quality and amount of patient information in the next version of our questionnaire.

Our instrument could be used in routine practice or in clinical trials by most nurses or by physicians prescribing, placing or using CVC, by psychologist in order to assess patient acceptance of and satisfaction with their care or by pharmacists in order to help select the best material for their patients. This is the first self-administered French multi-dimensional validated questionnaire measuring the use, appearance and pros and cons of the device as well as quality of life as perceived by patients using a CVC for treatment. This questionnaire was constructed using validated methodology. The Steering Committee monitored the whole construction procedure and followed the work of the focus and patient groups. This first statistical validation on 215 patients seems very promising and the questionnaire shows very satisfactory psychometric properties. Further validation studies are required on standard or specific populations and with different devices/trade manufactured product in order to confirm this first validation phase.

The construction and validation of the QASICC questionnaire was a secondary objective of the clinical trial presented here. The main objective was to compare surgically-inserted chest ports and radiologically-inserted arm ports for CVC in terms of mechanical, thrombotic and infectious events. So, in order to conclude more precisely, a large prospective multicenter study was launched in 2011 and was completed in December 2012. We hope that this study designed specifically for QASICC validation and involving nearly 1000 patients will confirm these first results.

\section{Acknowledgements}

We thank M. Yann Chateau, data manager of Antoine Lacassagne Cancer Center for data management.

\section{Conflict of Interests}

None declared.

\section{References}

[1] Galloway, M. (2010) Insertion and Placement of Central Catheters in the Oncology Patient. Seminars in Oncology Nursing, 26, 102-112. http://dx.doi.org/10.1016/j.soncn.2010.02.004

[2] Gallieni, M., Pittiruti, M. and Biffi, R. (2008) Vascular Access in Oncology Patients. CA: A Cancer Journal for Clinicians, 58, 323-346. http://dx.doi.org/10.3322/CA.2008.0015

[3] Sprangers, M.A., Cull, A., Groenvold, M., Bjordal, K., Blazeby, J. and Aaronson, N.K. (1998) The European Organization for Research and Treatment of Cancer Approach to Developing Questionnaire Modules: An Update and Overview. EORTC Quality of Life Study Group. Quality of Life Research, 7, 291-300. http://dx.doi.org/10.1023/A:1008890401133

[4] Falissard, B. (2008) Mesurer la subjectivité en santé: Perspective méthodologique et statistique. 2nd Edition, Masson, Paris.

[5] Hasson, F., Keeney, S. and McKenna, H. (2000) Research Guidelines for the Delphi Survey Technique. Journal of Advanced Nursing, 32, 1008-1015.

[6] Niederhuber, J.E., Ensminger, W., Gyves, J.W., Liepman, M., Doan, K. and Cozzi, E. (1982) Totally Implanted Venous and Arterial Access System to Replace External Catheters in Cancer Treatment. Surgery, 92, 706-712.

[7] Pullyblank, A.M., Carey, P.D., Pearce, S.Z., Tanner, A.G., Guillou, P.J. and Monson, J.R. (1994) Comparison between Peripherally Implanted Ports and Externally Sited Catheters for Long-Term Venous Access. Annals of the Royal College of Surgeons of England, 76, 33-38. 
[8] Kock, H.J., Pietsch, M., Krause, U., Wilke, H. and Eigler, F.W. (1998) Implantable Vascular Access Systems: Experience in 1500 Patients with Totally Implanted Central Venous Port Systems. World Journal of Surgery, 22, 12-16. http://dx.doi.org/10.1007/s002689900342

[9] Lilienberg, A., Bengtsson, M. and Starkhammar, H. (1994) Implantable Devices for Venous Access: Nurses’ and Patients' Evaluation of Three Different Port Systems. Journal of Advanced Nursing, 19, 21-28. http://dx.doi.org/10.1111/j.1365-2648.1994.tb01046.x

[10] Johansson, E., Engervall, P., Bjorvell, H., Hast, R. and Bjorkholm, M. (2009) Patients’ Perceptions of Having a Central Venous Catheter or a Totally Implantable Subcutaneous Port System-Results from a Randomised Study in Acute Leukaemia. Supportive Care in Cancer, 17, 137-143. http://dx.doi.org/10.1007/s00520-008-0449-6

[11] Maurer, M.H., Beck, A., Hamm, B. and Gebauer, B. (2009) Central Venous Port Catheters: Evaluation of Patients' Satisfaction with Implantation under Local Anesthesia. Journal of Vascular Access, 10, 27-32.

[12] Caljouw, M.A., van Beuzekom, M. and Boer, F. (2008) Patient's Satisfaction with Perioperative Care: Development, Validation, and Application of a Questionnaire. British Journal of Anaesthesia, 100, 637-644. http://dx.doi.org/10.1093/bja/aen034 